\title{
High Temperature Laser Based Drop on Demand Micro Joining of Thin Metallic Layers or Foils using Bronze Braze Preforms
}

\author{
Stefan Stein ${ }^{* 1,3}$, Johannes Heberle ${ }^{* 2,3}$, Michael Suchy ${ }^{* 1}$, Felix Tenner ${ }^{* 2,3}$, \\ Florian Hugger ${ }^{* 1}$, Stephan Roth ${ }^{{ }^{* 1,3}}$ and Michael Schmidt ${ }^{* 1,2,3}$ \\ ${ }^{* 1}$ Bayerisches Laserzentrum GmbH (blz), Konrad-Zuse-Str. 2-6, 91052 Erlangen, Germany \\ ${ }^{* 2}$ Institute of Photonic Technologies (LPT), Friedrich-Alexander-Universität Erlangen-Nürnberg, \\ Konrad-Zuse-Str. 3-5, 91052 Erlangen, Germany \\ ${ }^{* 3}$ Erlangen Graduate School in Advanced Optical Technologies (SAOT), Friedrich-Alexander- \\ Universität Erlangen-Nürnberg, Paul-Gordan-Str. 6, 91052 Erlangen, Germany
}

\begin{abstract}
In this paper a drop on demand based method of joining metallic layers of about $20 \mu \mathrm{m}$ thickness with $\mathrm{Cu}$-conductors of $100 \mu \mathrm{m}$ diameter is presented. The process is based on melting spherical preforms of copper based braze (CuSn12) with a liquidus temperature of $990{ }^{\circ} \mathrm{C}$ [1]. In the process, a braze preform is induced into a ceramic capillary, molten by a laser pulse and expelled out of the machining head via nitrogen overpressure. After a flight phase the braze droplet wets the surface of the electrode structure and the copper resulting in a firm joint after solidification. The shear strengths of the joints were measured to be $31 \mathrm{MPa}$ for joints on $\mathrm{Al}_{2} \mathrm{O}_{3}$ substrates and $37 \mathrm{MPa}$ for joints generated on LTCC substrates with screen printed Ag electrode structures. The shear strengths after temperature shock tests according to DIN EN 60068-2-14 indicate good performance of the joints in harsh environments. The average resistivity of a joint was tested by four wire testing and found to be $1.56 \pm 0.33 \mathrm{~m} \Omega$. The introduced setup is capable to join thin metallic layers of 30 $15 \mu \mathrm{m}$ thickness with cu conductors of $100 \mu \mathrm{m}$ diameter without the need of flux.
\end{abstract}

DOI: 10.2961/jlmn.2016.01.0021

Keywords: micro joining, laser droplet brazing, joining of foils, electronics, contacting, electrodes

\section{Motivation}

Drop on demand techniques are under investigation since about 1990 and became lately focus of considerable interest for research groups $[2,3]$. Yet most of the approaches generate droplets from inks or other fluids. The setup introduced in this paper however is capable to generate droplets of the bronze alloy $\mathrm{CuSn} 12$ with a liquidus temperature $\mathrm{T}_{\text {Liquid }}$ of about $1000^{\circ} \mathrm{C}$. The initial demand for the development of this drop on demand micro joining method was to obtain joints for piezo actuators to be integrated into structural parts via aluminum die casting [4]. Yet several industrial applications require the joining of foils or thin metallic layers with conductors. The demands on such joints are challenging for any joining method, since the metallic layers must not be damaged, yet a firm joint needs to be achieved. A method recently developed is laserbased drop on demand micro joining. The process is based on the already available laser droplet soldering processes $[5,6]$, however, since the necessary energies to melt the CuSn12 preforms are about eight times higher than the ones of tin based solder preforms of similar diameter, the laser power must be scaled up significantly.
The used braze preforms are generated by atomization followed by subsequent sieving, therefore deviations in diameter and volume as well as the formation of satellite particles can occur. If a constant pulse duration is chosen, two effects are likely to occur: If an above-average sized preform is inserted into the capillary, the pulse duration is not sufficient to thoroughly melt the braze preform which results in a blocking of the capillary. For comparably small braze preforms however, the pulse length will be long enough to perforate the substrate, resulting in its destruction. To counteract this effect, a pulse length control needs to be implemented to level out preform volume deviations. As it is not applicable to balance every braze preform and select the pulse length accordingly, another approach for pulse length control was pursued and will be described in this paper. 


\section{Methods}

\subsection{Laser drop on demand joining process}

The laser-based drop on demand (DOD) micro joining process can be divided into four main phases. First the preform is inserted into a capillary and irradiated with a laser pulse (phase 1), which heats the braze preform above liquidus temperature. During melting, wetting of the capillary occurs (phase 2) and the droplet is ejected out of the capillary by nitrogen overpressure (phase 3 ). After a flight phase, the droplet impinges on the joining area consisting of the electrode structure and the $\mathrm{Cu}$-wire, wetting both and forming a firm joint after solidification (phase 4, fig. 1).

1. irradiation 2. wetting of 3 . ejection 4. contacting

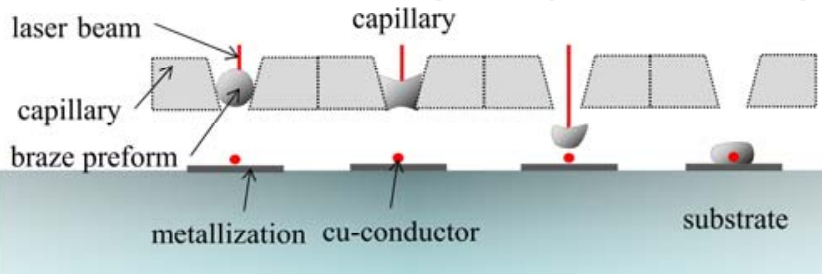

Fig. 1 Schematic of process phases

\subsection{System}

The laser used for the investigations is a fiber laser with a wavelength of $1070 \mathrm{~nm}$, a maximum optical output power of $200 \mathrm{~W}$ and a collimated beam diameter of $6.9 \mathrm{~mm}$. It is focused by a lens of focal length $\mathrm{f}=50 \mathrm{~mm}$ to form a laser spot diameter of $10.9 \mu \mathrm{m}$. The setup is operated with a focus offset, to obtain a broader beam diameter on the braze preform, since working in focus will lead to a perforation of the braze preform inside the capillary, resulting in fragmentary braze ejection. Using lenses with higher focal length to obtain a larger spot diameter on the braze preform surface did not proof a suitable approach, since due to the lower divergence of the beam, the substrate is exposed to higher power densities, which can result in perforations and a more volatile process. A nitrogen feed attached to a pressure regulator provides a defined nitrogen overpressure and is being monitored in situ by a pressure sensor. For beam deflection a dicroic mirror is used, thus a CCD-camera, which is coaxially aligned to the beam path can be used for process tuning and monitoring. Fig. 2 shows a sketch of the experimental setup.

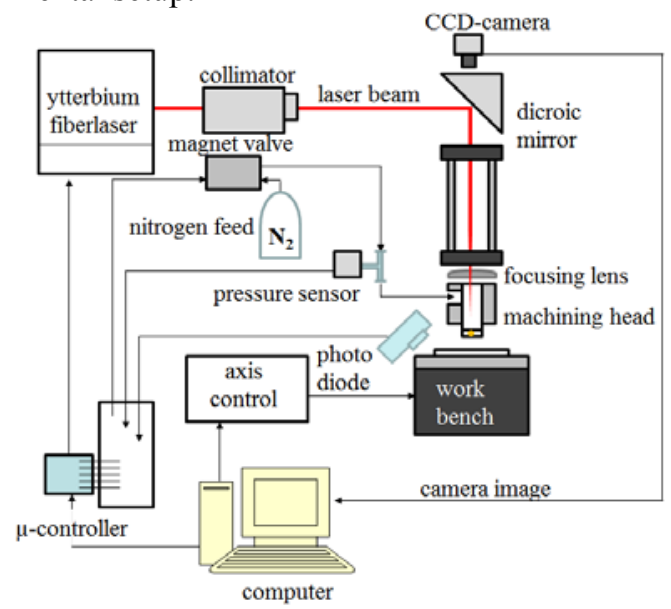

Fig. 2 Schematic of experimental setup
Since the orifice of the capillary has a diameter of about $600 \mu \mathrm{m}$, a precise alignment of the laser beam to the center of the orifice, as well as an alignment of the machining head to the joining area is crucial for good process results and must be ensured, to avoid perforations of the capillary by the laser pulse. Further, evaluating the CCD images enable an optical monitoring and evaluation of the capillary by image processing algorithms, which will be discussed in this paper in section 3.2. Additionally, a photodiode (PD) directed at the joint position enables the determination of the exact time of braze detachment by detecting laser radiation scattered on the joining area and thus can be used for process control (for details see 3.1). Conic shaped $\mathrm{WC} / \mathrm{Co}$ capillaries are used for standard tin based solder alloys in laser droplet soldering processes, however $\mathrm{WC} / \mathrm{Co}$ did not proof suitable for the use of $\mathrm{CuSn} 12$ preforms, since cobalt is prone to be wetted by copper [7] which results in large deviations of detachment times and premature thermal destruction of the capillary due to enhanced thermal stress. Therefore, an alternative capillary consisting of zirconia toughened aluminum oxide (ZTA) has been machined and characterized in [8] and is used in the scope of this work.

\subsection{Material properties}

The material used as braze preform is CuSn12. The physical properties of the used braze material have been summarized in [9] and are shown in table 1.

Table 1 Physical properties of bronze (CuSn12) [9]

\begin{tabular}{cc}
\hline Property & Value \\
\hline $\begin{array}{c}\text { Density at room } \\
\text { temperature }\end{array}$ & $\begin{array}{c}8776 \mathrm{~kg} / \mathrm{m}^{3} \text { (by the rule } \\
\text { of mixtures based on }\end{array}$ \\
$\begin{array}{c}\text { Specific heat at room } \\
\text { temperature }\end{array}$ & $\begin{array}{c}367 \mathrm{~J} /(\mathrm{kg} \mathrm{K})(\mathrm{by} \text { the rule of } \\
\mathrm{mixtures} \mathrm{based} \mathrm{on} \mathrm{[10])}\end{array}$ \\
$\begin{array}{c}\text { Enthalpy of fusion } \\
\text { Liquidus tempera- } \\
\text { ture }\end{array}$ & $91,3 \mathrm{~kJ} / \mathrm{kg}[11]$ \\
Solidus temperature & $1263 \mathrm{~K} \mathrm{[1]}$ \\
\hline
\end{tabular}

In the scope of the paper, joints on two different types of ceramic substrates commonly used in electronics packaging are used for investigations. The electrode structures on the substrates were applied by screen printing. The thermal conductivity of the used LTCC substrate is $3 \mathrm{~W} / \mathrm{mK}$ according to datasheet. The LTCC substrates has a thermal conductivity of $20-30 \mathrm{~W} / \mathrm{mK}$ [12], whereas the Ag electrode structure has $429 \mathrm{~W} / \mathrm{mK}$ [10].

\section{Process control}

\subsection{Pulse length control}

To compensate the effect of preform size deviations, a process control was implemented, which enables an interruption of the laser pulse after droplet detachment. The algorithm further is able to provide a post heating in order to elongate the laser pulse after detachment.

During joining, first the laser emission is enabled, allowing the microcontroller to trigger laser emission. The 
magnet valve is opened and the nitrogen overpressure builds up in the machining head. After a delay of $100 \mathrm{~ms}$, which is sufficient to build up the desired overpressure, the laser emission is triggered. The photodiode signal is monitored throughout the joining cycle. Once the droplet is detached from the capillary, laser radiation is scattered from the droplet and the substrate. This results in the photodiode signal rising above a defined absolute threshold value, triggering the interruption of the laser pulse. Fig. 3 shows the signal sequence of one joining process. If the PD-threshold value is not reached after $400 \mathrm{~ms}$ the pulse is interrupted to protect the machining head and capillary from thermal damage. The setup thus enables a precise determination of the moment of braze detachment from the capillary.

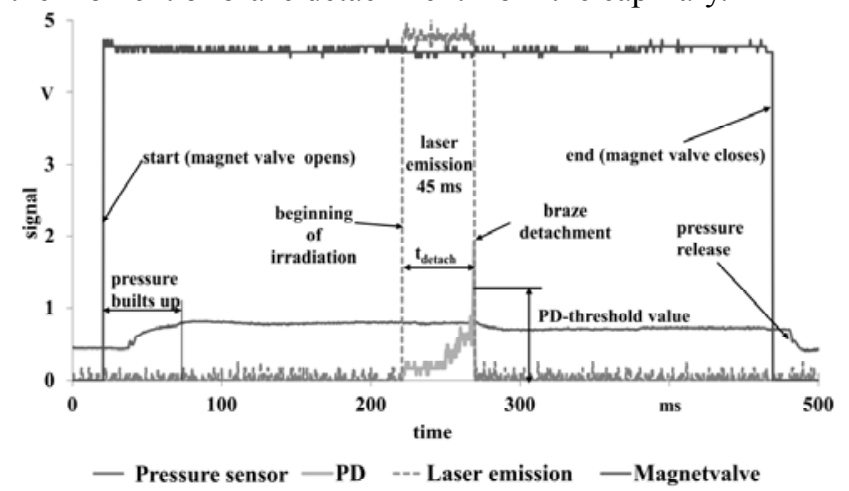

Fig. 3 Signal sequence during joining $\left(\mathrm{P}_{\text {Laser }}=140 \mathrm{~W}\right)$

\subsection{Capillary monitoring}

The capillary is the most important part of the setup determining the joint quality, since its orifice geometry determines the flight path of the droplet and its heat conductivity influences the inherent energy of the droplet. It is also the part of the system, which is exposed to intense thermal load cycles of about $800 \mathrm{~K}$ per joining cycle and thus requires a comprehensive monitoring regarding wear, shape deviations or blocking by braze residues. A Monitoring of the capillary by means of machine vision is therefore carried out, to detect faults, which can have adverse effects on the joint quality like partial perforation of the nozzle, due to improper alignment of the machining head to the laser beam, or the formation of braze residues.

In order to realize an automated nozzle monitoring, an algorithm has been developed, which evaluates the coaxially acquired image of the capillary. In order to assure a maximum image contrast, the focal plane of the focusing lens must match with the upper surface of the capillary. After the binarization of the image, the convex hull encircling all areas of value 1 (white) is calculated. The resulting binary image will now consist of only one area, representing the aperture of the capillary. Subsequently, the smallest circle enclosing the area is calculated. This circle serves for building a mask, which can then be compared to the initial binarized image. Dividing the total number of white pixels of the mask representing the perfect circle by the number of white pixels of the initial binarized image gives the area fraction of the nozzle which is blocked or contaminated with braze residues.
In order to estimate the error of the algorithm, perfect circles with a defined diameter (in pixels) have been analyzed. The results show an error of $7 \%$ for a capillary diameter of 100 pixel, which represents well the diameter of the image of the capillary orifice on the CCD. Thus with the algorithm it is possible to detect the development of braze residues inside the capillary over a number of process cycles.

\section{Results and discussion}

\subsection{Element analysis of cross section of laser droplet joint}

In order to estimate the quality of the bond, cross sections are analyzed by energy dispersive x-ray spectroscopy (EDX) mappings. Joints of $12.5 \mu \mathrm{m}$ Ag-foil and $100 \mu \mathrm{m}$ $\mathrm{Cu}$-wire have been investigated. The elements detected were $\mathrm{Ag}, \mathrm{Cu}, \mathrm{Sn}$ as well as $\mathrm{C}$, which can be attributed to the investment compound (fig. 4 A). The Ag-distribution in the joining area is particularly interesting, since it indicates mechanical and electrical contact between foil and joint. The Ag distribution is shown in fig $4 \mathrm{~B}$.

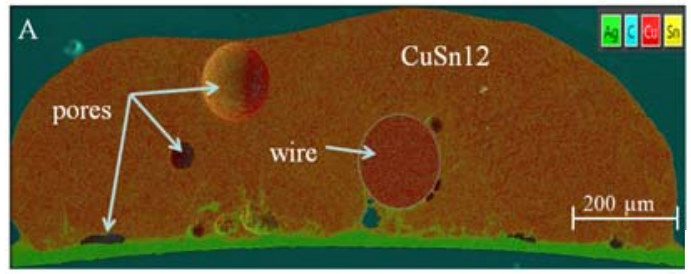

100 at $\%$ Ag

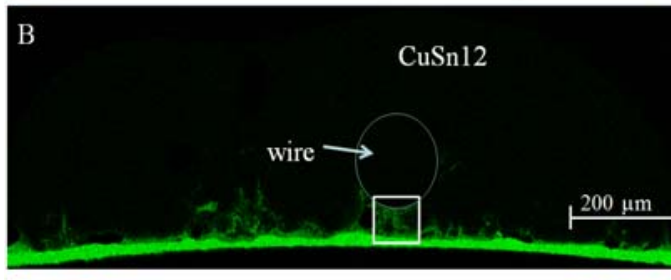

0 at\% $\mathrm{Ag}$

Fig. 4 EDX mapping of $12.5 \mu \mathrm{m} \mathrm{Ag-foil} \mathrm{joined}$ with $100 \mu \mathrm{m} \mathrm{Cu}$-wire using CuSn 12 braze, $\mathrm{P}_{\text {Pulse }}=125 \mathrm{~W}, \mathrm{p}_{\text {Nitrogen }}=110 \mathrm{mbar}$ $\mathrm{ETH}=20.00 \mathrm{kV}$; Vac. $1.12 \times 10^{-5} \mathrm{mbar}$

The EDX mapping indicates a partial solution of the Ag-foil and Ag-traces up to $100 \mu \mathrm{m}$ above the initial foil position. In order to explain this Ag-distribution a detail of the joining area marked with white frame, is analyzed. Fig. 5 shows the atom fractions of the elements $\mathrm{Cu}, \mathrm{Sn}$ and Ag of this detail of the joint.

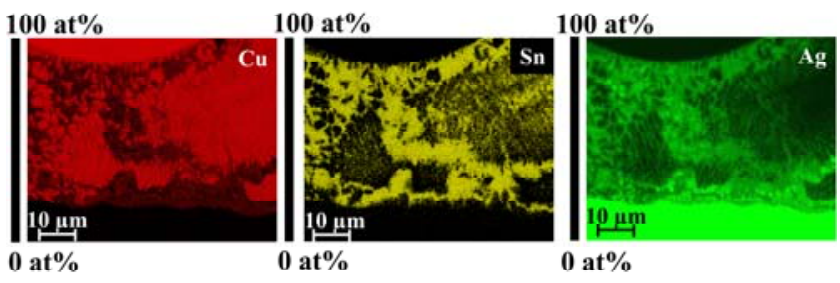

Fig. 5 Detail of EDX mapping for $\mathrm{Cu}, \mathrm{Sn}$ and $\mathrm{Ag}$

A formation of dendritic $\mathrm{Cu}$ segregations due to the higher melting temperature of $\mathrm{Cu}$ compared with $\mathrm{Ag}$ and Sn $[8,10]$ can be seen. Further more, the development of $\mathrm{Cu}$-dendrites on the wire surface can be observed, indicating a firm metallurgical bond between wire and braze ma- 
terial. The formation of dendritic structures indicate high cooling rates $[9,13]$, which is supported by thermocouple measurements carried out in the scope of this paper. In order to assess the time temperature evolution during the joining process, a Type $\mathrm{K}$ thermocouple of $\mathrm{NiCr} / \mathrm{NiAl}$ alloy with a diameter of $0.75 \mu \mathrm{m}$ was used. With this diameter it resembles the diameter of the $\mathrm{Cu}$-conductor rather well and in addition has faster reaction times than thermocouples with larger diameter. The sample rate used for recording the time-temperature evolution during joining was $200 \mathrm{~Hz}$. The time response according to datasheet was $0.1 \mathrm{sec}(96 \%$ of value in moving gas). During the measurement a droplet of molten braze has been placed directly onto the thermocouple. The measurements indicate cooling rates of up to $80000 \mathrm{~K} / \mathrm{s}$. Within 25 to $30 \mathrm{~ms}$ after detachment the droplet cools below liquidus temperature again. Due to the $\mathrm{Cu}-$ depletion of the melt during solidification, AgSn rich phases form ab bridge between Ag-foil and wire. Therefore, the formation of AgSn rich phases with lower liquidus temperature than $\mathrm{Cu}$ can be accounted to be the responsible mechanism for the observed Ag distribution in the joining area. Further more, a perforation of the foil cannot be observed.

\subsection{Mechanical strength and resistivity of obtained joints}

Since it is not applicable to carry out sheartests on foils, joints were generated on two common ceramics for electronic applications. One substrate system used, was an $\mathrm{Al}_{2} \mathrm{O}_{3}$ based high temperature cofired ceramic (HTCC) of the company Siegert Electronics. The other system was a Heraues HL2000 no shrink low temperature cofired ceramic (LTCC) tape consisting of alumina particles $\left(\mathrm{Al}_{2} \mathrm{O}_{3}\right.$ about $20 \%-40 \%$ wt of fired product), and glass frit particles $\left(\mathrm{SiO}_{2}, \mathrm{CaO}, \mathrm{B}_{2} \mathrm{O}_{3}, \mathrm{MgO}, \mathrm{SrO}, \mathrm{TiO}_{2}, \mathrm{PbO}\right)$ that allow a lower sintering temperature, held together by an organic binder $[10,14]$. The joints were carried out on screen-printed Ag electrode structures of $20 \mu \mathrm{m}$ thickness, which have been joined with annealed $\mathrm{Cu}$-wires of $100 \mu \mathrm{m}$ diameter. The shear tests were performed using a XYZTEC shear tester Condor 150-3. The velocity of the shear chisel was $5 \mathrm{~mm} / \mathrm{s}$. The measurement precision is $0.1 \%$ of the absolute value. The shear tests have been carried out in initial state and after temperature shock tests according DIN EN 60068-2-14 (1000 cycles $-40^{\circ} \mathrm{C} /+125{ }^{\circ} \mathrm{C}$ dwell time: $10 \mathrm{~min}$, transfer time: $10 \mathrm{~s}$ ). The results are shown in fig. 6 .

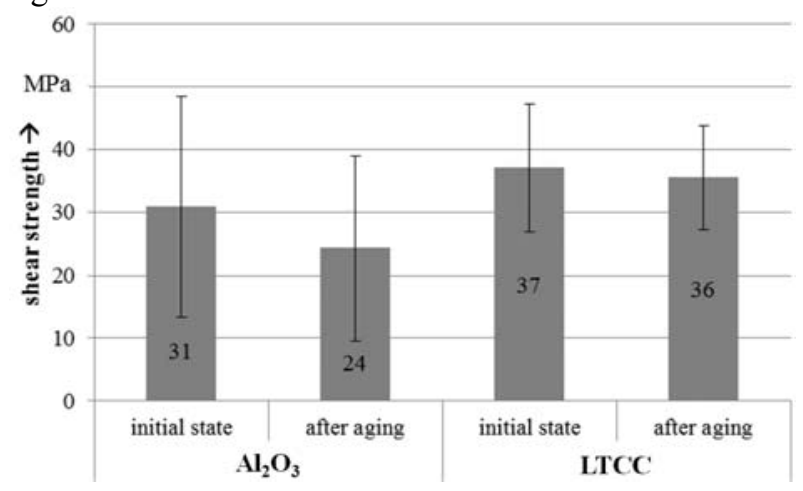

Fig. 6 Shear force of joints created on $\mathrm{Al}_{2} \mathrm{O}_{3}$ ceramics and Heraeus HL 2000 LTCC tape with $20 \mu \mathrm{m} \mathrm{Ag}$ metallisations $(\mathrm{n}=10)$
The joints on $\mathrm{Al}_{2} \mathrm{O}_{3}$ substrates show reduced shear strength and higher standard deviations before and after temperature shock tests in comparison to the joints on LTCC ceramics, which can be accounted to the higher heat conductivity of the $\mathrm{Al}_{2} \mathrm{O}_{3}$ substrates of about $19 \mathrm{~W} / \mathrm{mK}$ in comparison to $3 \mathrm{~W} / \mathrm{mK}$ for the LTCC ceramic substrate (values according to the respective datasheets), which leads to faster solidification of the braze material and results in reduction of melt flow and diffusion and thus shear strength.

The results show good temperature shock resistance of the joints on LTCC ceramic substrates, whereas the shear strength drops by $18 \%$ for the $\mathrm{Al}_{2} \mathrm{O}_{3}$ samples. A measure to counteract heat loss due to high thermal conductivity of the substrate can be prolonged irradiation of the joint after braze detachment to enhance diffusion and meltflow and will be topic of further investigations. For the used LTCC ceramic substrates in most of the cases the strength of the joint exceeded the strength of the ceramic substrate, leading to failure in the ceramic, since the joint with the metallisation pad is ripped out of the ceramic substrate, leaving a shell shaped crater with shear cracks (fig. 7).
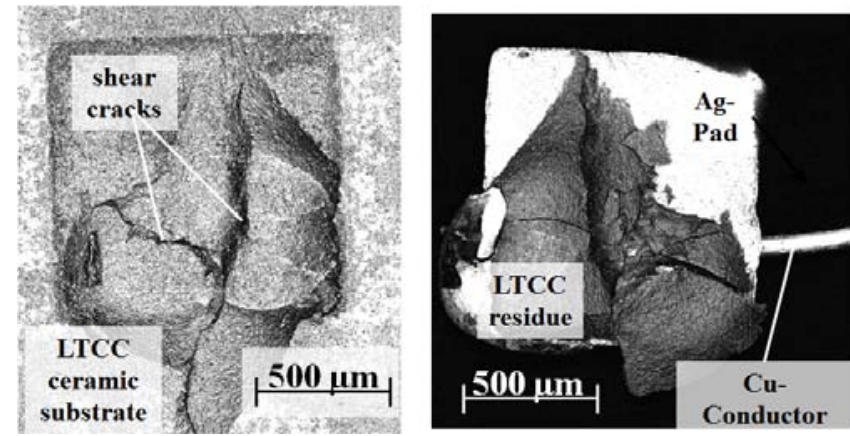

Fig. 7 Crater in LTCC ceramic HL 2000 with shear cracks (left) and joint with ceramic residue on the Ag-pad, (right)

Investigations on cross-sections of joints occasionally showed micro cracks formed at the edges of the solder pads of LTCC substrates.

To distinguish, weather this effect can be accounted to the shrinkage of the joint during solidification or to specimen preparation like grinding and polishing of materials with significantly differing hardness can not yet be clarified due to its rare occurrence and is topic of further investigations.

Furthermore, the resistivity of the joint has been tested using the four wire testing method. A Sefelec MGR10 resistance measurement unit had been used. The measuring tips were placed as close to the droplet as possible without touching it. The measured resistance of the joint was $1.56 \pm 0.33 \mathrm{~m} \Omega(\mathrm{n}=8)$ and is lower than the resistivity calculated for the $\mathrm{Cu}$-wire of $100 \mu \mathrm{m}$ diameter and $1 \mathrm{~mm}$ length of $2.2 \mathrm{~m} \Omega$. The joint can therefore be estimated to be an ideal electric transition.

\subsection{Evolution of braze residues in the capillary}

With the capillary monitoring via image-processing algorithm it is possible to evaluate the formation of braze residues inside the capillary over time. The capillary shape and condition is crucial for reproducible braze detachment 
and positioning accuracy of the joint [7]. Fig. 13 shows the evolution of braze residues inside the capillary over a process cycle of 125 joints, carried out using the imageprocessing algorithm (fig. 8).

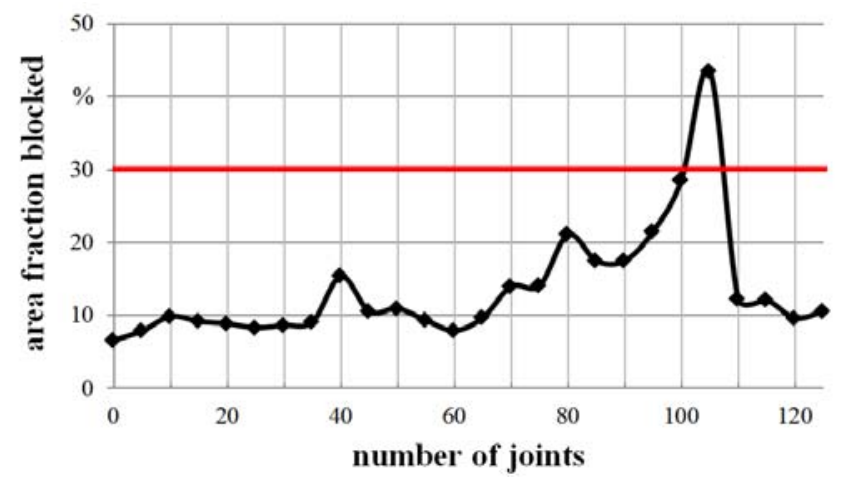

Fig. 8 Evolution of braze residues over 100 process cycles with threshold value indicating blocked capillary

$$
\left(\mathrm{P}_{\text {Pulse }}=125 \mathrm{~W} ; \mathrm{P}_{\text {Nitrogen }}=110 \text { mbar }\right)
$$

At an increased number of process cycles $(n=90-105)$, the capillary shows clogging with braze residues. In order to understand the underlying mechanism, an EDX analysis of the inner cavity of the capillary after 100 joining cycles has been carried out. Aside of the obvious presence of the elements aluminum and oxygen, phosphorus was detected (fig. 9).

$100 \mathrm{at}^{\mathrm{o}} \mathrm{o}$

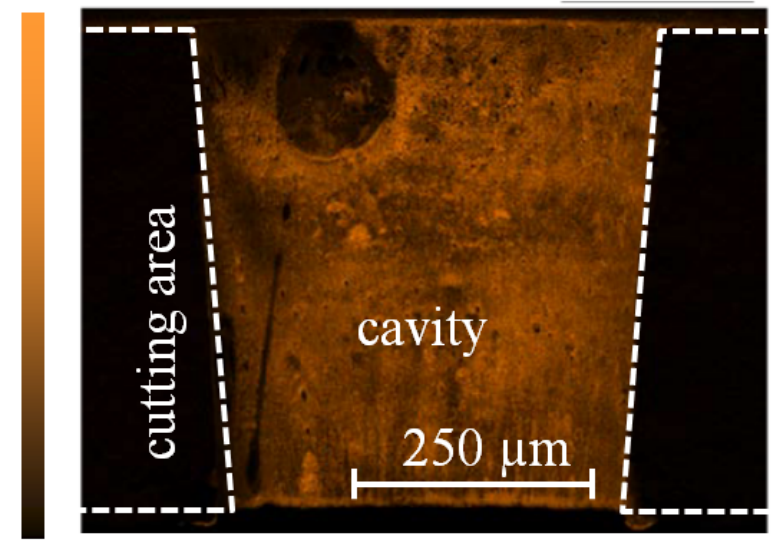

$0 \mathrm{at}^{\mathrm{o}} \%$

Fig. 9 Sectional view of capillary with element mapping of phosphorus in the cavity after 100 process cycles

The presence of phosphorus in the braze alloy and thus in the capillary can be explained, since it is added in small quantities $(0.01 \%)$, for deoxidation of copper-tin braze during remelting and to increase moldability, expand solidification temperature and increase electric conductivity of the alloy [1]. The reaction product of oxygen and phosphorus is phosphorus pentoxide, which can form slag $[1,15]$ and can be assumed to form the found residues. Regardless the formation of phosphorus slag residues inside the capillary, clogging of the capillary by braze can be counteracted by using a laser pulse of $200 \mathrm{~ms}$ length and a pulse power of $130 \mathrm{~W}$ at a overpressure of $120 \mathrm{mbar}$, to clear the capillary of braze residues. This measure needs to be taken, once the blocked area fraction exceeds a threshold value of $30 \%$. Values below this threshold do not show adverse influences on the joining process and thus can be ignored.

\section{Summary and outlook}

Laser based drop on demand micro joining is a novel flux less approach for the thermally stable joining of thin metallic layers or foils with $\mathrm{Cu}$-conductors. The introduced setup allocates a capillary monitoring, enabling an observation of the formation of braze residues during multiple joining cycles. Countermeasures have been developed to ensure stable joining results. Further, the system technology enables a pulse length control, which is necessary to counteract deviations in braze preform volume.

The characterization of the joints indicate mean shear strengths of $31 \mathrm{MPa}$ for joints carried out on $\mathrm{Al}_{2} \mathrm{O}_{3}$ substrates and $37 \mathrm{MPa}$ for joints carried out on LTCC substrates. The shear strengths after temperature shock tests according to DIN EN 60068-2-14 indicate good performance of the joints in harsh environments. The average resistivity of a joint was tested by four wire testing and found to be $1.56 \pm 0.33 \mathrm{~m} \Omega$ which is lower than calculated resistivity of $100 \mu \mathrm{m} \mathrm{Cu}$-wire of $1 \mathrm{~mm}$ length and thus negligible.

The introduced setup is capable to join thin metallic layers of about $15 \mu \mathrm{m}$ thickness with cu conductors of $100 \mu \mathrm{m}$ diameter without the need of flux. Further materials e.g. Au seem to be feasible to be joined flux less and thermally stable with the introduced setup. Thus, even pure $\mathrm{Au}$ systems seem to be possible to be generated with the introduced setup. Such single element systems to do not show degeneration due to the formation of intermetallic phases or CTE mismatch and further more are not prone to contact corrosion. Further tasks are the refinement of the analytical model, to enhance process understanding, as well as setting up a simulation model and correlating it with the experiment to quantify process influences like overpressure and influence of a post heating pulse on the time temperature evolution in the joining area.

\section{Acknowledgment}

This research is supported by the Deutsche Forschungsgemeinschaft (DFG) in context of the Collaborative Research Centre/Transregio 39 PT-PIESA, subproject A04. In addition, the authors gratefully acknowledge funding of the Erlangen Graduate School in Advanced Optical Technologies (SAOT) by the German Research Foundation (DFG) in the framework of the German excellence initiative

\section{References}

[1] N. N.: "Kupfer-Zinn-Knetlegierungen - Zinnbronzen". (Deutsches Kupfer-Institut, Düsseldorf, 2004) 14.

[2] D. M. Harris, T. Liu, and J. Bush: Experiments in Fluids, 56, (2015) 56.

[3] J. Luo, L. Qi, S. Zhong, J. Zhou, and H. Li: Journal of Materials Processing Technology, 212, (2012) 2066.

[4] M. Schwank1, M. Rübner, R. F. Singer, and C. Körner: Procedia Materials Science, Symposium of Materials Science Engineering, B6 - Hybrid Structures, (2013) 166. 
[5] L. Yang, W. Liu, C. Wang, and Y. Tian: 12th International Conference on Electronic Packaging Technology and High Density Packaging (ICEPT-HDP), Shanghai, (2011).

[6] E. Zakel, L. Titerle, T. Oppert, and R. G. Blankenhorn: International Conference on Electronics Packaging, Tokio, (2002).

[7] S. Curiotto, and D. Chatain: Scripta Materialia, 60, (2009) 40.

[8] S. Stein, J. Heberle, F. J. Gürtler, K. Cvecek, S. Roth, and M. Schmidt: 8th International Conference on Laser Assisted Net Shape Engineering, Physics Procedia, 56, (2014) 709.

[9] A. Jeromen, A. Kuznetsov, and E. Govekar: 8th International Conference on Laser Assisted Net Shape Engineering, Physics Procedia, 56, (2014) 720.

[10] R. C. Weast: "CRC Handbook of chemistry and physics: A ready-reference book of chemical and physical data", (CRC Press, Cleveland, Ohio, 1974).

[11] W. Zhai, W. L. Wang, D. L. Geng, and B. Wei: Acta Materialia, 60, (2012) 6518.

[12] F. Raether, J. Meinhardt, A. Klimera, and J. Ruska: Proceedings of Materials Week, (2000).

[13] S. Kou: "Welding metallurgy", 2nd ed, (WileyInterscience, Hoboken, N.J., 2003).

[14] K. M. Nowak, H. J. Baker, and D. R. Hall: Appl. Phys. A., 84, (2006) 267.

[15] N. N.: Industrial Standard: DIN V 17900:1999-03 "Kupfer und Kupferlegierungen - Übersicht überZusammensetzungen und Produkte", Deutsches Institut für Normung, Beuth, (1999).

(Received: May 22, 2015, Accepted: February 2, 2016) 